folk/ed. Derg, 2022; 28(1)-109. sayı

DOI: $10.22559 /$ folklor.2060

\title{
Tengricilikte Bizden Yeyler: Şulum, Çer ve Çor
}

\author{
Shulum, Cher, Chor Demons in Tengrismi
}

\section{Aynur Gazanfargizi*}

\begin{abstract}
Öz
İyeler her zaman araştırmacıların dikkat merkezindeki bir konudur. Gizemi ise halâ tam olarak çözülememiştir. İyi huylu ve kötü huylu olmaları, insanlara faydalı iyenin bir anda zarar vericiye dönüşmesi vs bir çok konu henüz araştırmacılar tarafından açıklığa kavuşturulmamıştır. İye pek çok kez "ak iye", "kara iye” şeklinde yazılmış, çizilmiştir. Bu tür ikiye ayırma, bizce, iye kavramını anlamayı bir kez daha zorlaştırabilir. Bu yüzden iye ne zaman bizden yey'e ("ak iye" "kara iye”ye) dönüşebilir, bunu doğru algılamak gerekir. Dikkatlice incelendiğinde Şulum, Çer ve Çor iyelerinin de bu kabilden iyelere ait olduğu görülmektedir. Çer hayvanlara, Çor bitkilere musallat iyelerdir. Şulum özellikle pasaklı insanlara musallat olur. Bu iyelerin iyi yanlarından bakacak olursak, Çor iyesi bağ iyesi olarak bilinir ve bahçenin bereketini arttırır. Çer iyesi hayvanların sağlıklı ve uzun ömürlü olmasını sağlar. Şulum iyesi temizliği temin eder. Anlaşıldığı üzere, her üç iye iyi huylu olmasına rağmen, insanların hafızalarında yarardan çok verdikleri zarar ile kalmıştır. Bunun sebebi insanoğlunun gördüğü zarardan psikolojik olarak etkilenmesi ve
\end{abstract}

Geliş tarihi (Received): 16-11-2021- Kabul tarihi (Accepted): 7-01-2022

* Doç.Dr., Bakü Hazar Üniversitesi Diller ve Edebiyatlar Departmanı (Bakı Khazar University Department of Languages and Literatures) Azerbaijan. aynurqezenferqizi@yahoo.com. ORCID 0000-0003-1415-2518 
iyelerin hangi seviyede zararlı olabileceği ihtimalini unutmamasıdır. Zamanla bu iyelerin sadece kötü yönleri hatırlanmış ve bizden yey ("kara iye") olarak literatüre geçmiştir. Makalemizde bu kavram kargaşasına açıklık getirmek, iyelerin özelliği, Türk halkları folklorundaki işlenme durumları ve Çer, Çor, Şulum hakkında kısa bilgi vermeye çalıştık.

Çalışmanın amacı Şulum, Çer, Çor iyelerini araştırmak, iyelerin ve "bizden yeyler"'in Tengricilikteki yerini belirlemektir. Bunun yanı sıra, her üç iyenin isminin anlamını belirlemektir. Makalede alan araştırması, tarama yöntemi ve karşılaştırmalı metot kullanılarak iyeler hakkında yeniden genel bilgi verilmiştir.

Anahtar sözcükler: tengricilik, iye, bizden yeyler, çer, çor, şulum

\begin{abstract}
İye (angel in Tengrism) are always a topic in the center of attention of researchers. The mystery is still not fully resolved. Despite hundreds of studies, God, it's angel and demons still doesn't attract the attention of researchers. İye was mentioned like as "ak iye (angel)", "kara iye (demon)" for many times. In my opinion, this kind of bifurcation, can make harder to understand the meaning of iye once again. That's why it's important to undestand as a result o what iye(angel) turn into demon completely. When viewed carefully, It seens that, the iyes of Şulum, Çer ve Çor also belongs to such angels. Çer haunted by animals and Çor by plants. Şulum especially haunted by scruffy people. Let's glance to their good habits. Çor iyesi is famous as an angel of garden and increase the fertility of garden. Çer iyesi ensures healthy and longevity of animals. hayvanların sağlıklı ve uzunömürlü olmasını sağlar. Şulum iyesi ensures the celanless. As we understood, despite all the three iye being wellmannered, remained in people's memories with more hard than good. The result of this is the pysycological impact of harm of human from the damage and not forgetting the possibility at what level iye can be dangereous. In the lenght of time, only the bad aspects of iyes remembered and entered the literature like as "kara iye". It will be seek the confusion of the meaning of "iye" and "bizden yey", also, the characteristics of the iyes of Şulum, Çer and Çor will be learned. The aim of this study is to research the members of Şulum, Çer, Çor, and to determine the place of the members and us yey in Tengrism. Besides, to research the meaning of all three demons (bizden yey) the meaning of their names. In this article, general information about iyes is given again by using field research, scanning method and comparative method, and the confusion of concepts between iye and bizden yey is investigated.
\end{abstract}

Keywords: tengrism, iyelbizden yey (angelldemon), cher, chor, shulum

\title{
Extanded summary
}

İyes have attracted the attention of many researchers until today, a lot of research has been done about it. Despite, mostly researchs were about of iye on Tengrism, the correct conclusion couldn't be reached. In our opinion, the reason that delayed getting the right result so long was mostly to search for the iyes only in the folklore of the Siberian Turks. 
According to the research, it is possible to say that the possessors are generally present in the mythological texts of all Turks. The system of iyes is divided into upper world, middle world and lower world of iyes. Turks who accepted Islam actually continued to keep the iyes alive in a way. Of course, although the names of these entities were Islamized over time under the heavy influence of Islam, when we watch carefully, it is seen that they are nothing but the books in Tengrism.

According to the Tengrism belief, God created the owner - the iye of everything and put it into the service of mankind. We frequently come across both good and bad natures of these mythological entities, who are considered to be the "owner of their place". Hitonic entities - doing harm, are referred to as "yegs" or "yeys from us(demons)" in mythological texts. Interestingly, although only the bad aspects of the iyes remain in people's memories, we actually think that it would be wrong to divide them into good or bad. I think the way you treat books determines their temper.Because books own where they are.

For example, when the owner of the garden, known as the "vineyard iye", treats him with respect, plucks the fruit from the garden with permission, greets him when entering the garden, and entrusts the garden to the iye on his way out, the crop will be plentiful. When the iye is disrespected, it cuts off the fertility of the garden and harms it. Mankind thought that nature was a gift from Tengri and treated it accordingly. In our opinion, over time, as this criterion of respect was forgotten, the iyes were divided into two. Çer and çor seems to be a disease name at first glance.

They remain in people's memories only as the name of the disease. In order, to better understand these iyes, it is necessary to review the texts about them thoroughly.According to the belief, if the horse gets sick, if the hair falls out, if the horse is weak, it has touched the horse. At night, an Alkarisi (demonic iye) or a jinn comes and rides a horse, and therefore sweats. In this way, the horse is cold and Çer touched. They save the animal from this disease with a special paste. There is a phrase used among the people when there is no crop: "Çor hit the crop". When the heads of the plants turn yellow and the stems dry, it is believed that the iye disease damages the plants. It is believed that the unseasonal yellowing and drying of the trees in the forest is due to the disease of rot.

Another famous expression that is very common in Azerbaijan is "you look like a Şulum", "you are like a Şulum". This expression is generally used for people who are scruffy, dirty and neglected.The word of Shulum has remained in our language as an idiom. The most important feature of the iye, which has various names such as şulum, şulbu, çulbu, is that it haunts scruffy people. It is understood from the displacement of the very common ş/ç sounds in Turks that the words Şulum and çulum come from the same origin. Although its name is written differently, this book haunts scruffy people in all Turks to which it belongs, forcing them to stay clean.

In order to reveal the mysteries of Tengrism, it is necessary to investigate the iye and their properties. When the iye is mentioned in today's folklore, concepts such as god and deity come to mind with the influence of the West, which has prevented them from being 
investigated and revealed in the right direction for a long time. In the ancient Turkic belief the iye is owner, and lives around the objects owns. That is, what it expresses is the book itself. Since there is the iye of everything that exists in the Tengrism belief, ancient times require people to be respectful towards everything around them. Unfortunately, this situation shows that many issues about Tengrism remain closed.

As a result of our research, it has been understood that although the members of Şulum, Çer and Çor are referred to as "black iye" in the literature, they can turn into harmful because of disrespect. Tengri sent the iye - the owner of everything not to harm the mankind, but to be useful them. It compelled people to be respectful towards them.

\section{Giriş}

İyeler günümüze değin bir çok araştırmacıların dikkatini çekmiş, hakkında çokça araştırma yapılmıştır. Tengricilikle ilgili yapılan araştırmalar en çok iyeler üzerine olsa da (Tanyu, 1986, Anoxin, 1924, Menges, 1976, Tokarev, 1982, Nadjip, 1979 vs.), doğru sonuca bir türlü var1lamamıştır. Doğru sonucu almayı bu kadar geciktiren sebep, bizce, çoğunlukla iyeleri sadece Sibirya Türklerinin halkbiliminde aramak olmuştur. İslam'1 kabul etmiş Türklerin zamanla iye yerine melek'i koysalar da eski isimlerini korudukları da bir gerçektir. Bazen İslami isim ve ya motif eklendiği için de araştırmacıların dikkatini çekmeyen iyeler halkbiliminde yaygındır. İyeler karşımıza bazen bir deyimde, bazen masalda, bazen de inamlarda çıkmaktadır. Bu da eski inancın izlerinin hafızalardan tam anlamıyla silinip gitmediğini belirler. Malesef, bu isim değişikliği çoğu zaman araştırmacıların iyelerin izini halâ eski inançlarda kalmış Sibirya Türklerinde aramaklarına yol açmıştır. Yapılan araştırmalara göre, iyelerin genel olarak tüm Türklerin mitolojik metinlerinde mevcut olduklarını söylemek mümkündür. İyeler sistemi üst dünya, orta dünya ve alt dünya iyeleri olarak bölünmüştür. İslam’ı kabul etmiş Türkler de aslında iyeleri bir şekilde yaşatmaya devam etmişler. Tabi ki, zamanla İslam'ın ağır etkisi altında bu varlıkların isimleri islamlaştırılsa da, dikkatlice izlediğimiz zaman onların Tengricilikteki iyelerden başkasının olmadığı görülmekte. Bu konuya aşağıda değinilecektir.

İye, idi, ige kavramlarının tarihi kaynaklarda da birden çok anlamda kullanıldığını görmekteyiz. Örneğin, idi eski yazıtlarda "sahip" anlamını verirken, "Kutaatgu bilig” eserinde "Tanrı" anlamında kullanılmış (Kaçalin, 2019: 332), Kaşgarlı ise hem "efendi, sahip", hem de "Tanrı" anlamlarının olduğunu yazmıştır (Asker, 2006: 14). "Lügat-1 Çağatay ve TürkîOsmânî”de ise "idi” ve "izi” sözleri arasında fark oluşturulmuş ve izi’nin anlamının "Tanrı", idi’nin anlamının ise "sahip, malik” olduğu belirtilmiştir (Buhari, 1882:98).

Halkbilimşinaslıkta senelerce Batı etkisinde kalınarak ciddi bir hata olarak iye yerine tanrıça kelimesi kullanılmış ve "ay tanrıçası”, "su tanrıçası”, “dağ tanrıçası” ve s. gibi anlayışlar literatüre girmiştir. Oysa, burada tanrıça" kelimesi yerine "iye" kelimesi kullanılırsa, kavramın daha anlaşılır olacağını düşünmekteyiz.Öte yandan daha büyük yanlış, kanımızca, iyeleri açıklarken İslami meleklerle kıyaslanılmaya çalışılmasıdır. Örneğin, P.Ergun iyelerin kavram kargaşasının doğru anlaşılmasını açıklamaya çalışırken "İyelere İslami inançtaki melekler ve koruyucu ruhlar bağlamında yaklaşılırsa, çözümün kolaylaşması mümkündür” 
(2019:11) diye yazarken aslında Tengricilik'in de İslam gibi tektanrılı olmasını anlatmak istemiştir. Fakat yine de belirtelim ki, Ergun'un bu düşüncesini kabul etmemiz mümkün değildir. İye ve Tanrı kavramlarının karmaşık olması fikri doğrudur, fakat İslami yaklaşım durumu bir az daha karışık hale getirir.

Ilk bakışta sanki İslam'ı kabul ettikden sonra Türkler sadece Tengri sözü yerine Allah, iye yerine meleği koymuşlar. Günümüzde halâ yaşanan bir çok ritüel, İslam'ın etkisinde gerçekleşmiş gibi görünse de, aslında derinine incelendiğinde Tengriciliğin etkisi açıkça hissedilir. Elimizdeki metinlerden de anlaşılmakta ki, Türkler İslam'ı kabul ederken başlangıçta Allah adını da kendi dillerindeki şekli ile kullanmışlardır. Örneğin, 12. Yy’da Fahrettin Mübarekşah; "Türkler arasında yaşayan Tanrı adlarının Arapça ve Farsça karşılığı olarak Tengri - Allah, Ulu Tengri - Hudavend, İdi - Hudavend şeklindedir" notunu düşmüştür (bknz:Nizami, 1995:87).

\section{1. İyeler ve bizden yeyler hakkında}

Tengricilik inancına göre, Tanrı yeryüzünde yarattı̆̆ı her şeyin sahibini - iyesini de yaratmış ve insanoğlunun hizmetine sunmuştur. "Oldukları yerin sahibi” (Beydili, 2015: 49) olarak kabul edilen bu mitolojik varlıkların hem iyi, hem kötü huylularına sıkça rastlamaktayı. Kötülük yapan hitonik varlıklar mitoloji metinlerinde "yeg"ler ve ya "bizden yeyler" olarak geçmekte. İyelerin aksine "bizden yeyler" insanların malını, kazanını, elbisesini, pirincini, yağını çalıp pilav yapar, elbiselerini giyer dans eder (Ferzeliyev, 1994: 50, Acalov, 1988: 51-52). Yani, bizden yeyler iyeler gibi koruyucu ve iyiniyetli değildir. Sinirlendirilince, hoşuna gitmeyen davranış sergileyince kendini kaybeder ve zarar verir. Örneğin, Çor, Çer bu kabilden olan varlıklardır. Halk arasında sıkça kullanılan "Çer deymiş", "Çor vurmuş" (Gazanfargizi, 2011) ifadeleri fikrimizi onaylar niteliktedir. Örneğin, at hastalandığı zaman "ata Çer değdi (Çer dokandı)", mahsül az olduğu, ya da zayi olduğu zaman ise "mahsulü Çor vurdu" denilir (Gazanfargizi, 2011). İlginçtir ki, iyelerinin sadece kötü yanları insanların hatırasında kalsa da, aslında onların iyi ve ya kötü olarak ikiye ayrılmalarının yanlış olacağı kanısındayız. İyelere karşı davranış biçiminin onların huyunu belirlediğini düşünüyorum. Çünki, iyeler bulundukları yerin sahibidirler. Örneğin bahçenin sahibi olarak bilinen "Bağ iyesi” bahçenin sahibi ona saygılı davrandığında, bahçeden meyvayı izin alarak kopardığında, bahçeye girerken selamlaşıp, giderken bahçeyi iyeye emanet ettiğinde (Acalov, 1988: 51) mahsul bol ve bereketli olur. Saygısızlık gördüğünde ise bahçenin betini bereketini keser ve zarar vermiş olur (Ferzeliyev, 1994: 49). Bu Tenricilikte insanı etrafindaki her şeye saygılı davranmaya mecbur kılar. İnsanoğlu doğanın Tanrı'nın bir emaneti olduğunu düşünür ve ona göre muamele yapardı. Kanımızca, zamanla, bu saygı kriteri unutuldukça iyelerin ikiye ayrımı da gerçekleşmiştir.

\section{2. Çer ve çor iyeleri/Bizden yeyleri}

Çer ve çor ilk bakışta bir hastalık adı gibi görünmektedir. Onlar insanların hafızalarında sadece hastalık adı olarak kalmakta. Bu iyeleri daha iyi anlamak için onların hakkındaki metinleri de iyice gözden geçirmek lazım. Örneğin, at Çer'i ne zaman kapar? 
İnanca göre, eğer at hastalanırsa, tüyleri dökülürse, zayıflarsa çer değmişdir. Gece Alkarıs1 yahut cin gelip ata biner, sürer ve bu yüzden de at terler. Böylelikle de at soğuk algınlığ1 geçirir ve çer değmiş olur (Gazanfargizi, 2011). Atın çer hastalığına illa ki üçharflilerin binmesi sonucu kapılması, kanımızca, tesadüf değildir. Üçhrafliler gaipte yaşadığına inanılan varlıklardır. İyeler de aynı şekilde gaipte yaşar. Bu bakımdan üçharfliler ile Çer'in insanların şuurunda birbiri ile ilintili olması kuvvetle muhtemel. Peki, bu hastalıktan atı kurtarmak için ne yapılır? Çer hastalığından kurtarmak için erikten hazırlanmış özel bir karışım atın vücuduna sürüldüğü ve sıkıca sarıldığı zaman at terler ve hızlıca iyileşir (Gazanfargizi, 2011).

Mahsüle dadanan Çor: Halk arasında yine mahsül olmadığı zamanlar kullanılan bir ifade var: "Mahsülü Çor vurmuş". Çor, yukarıda da belirttiğimiz üzere, bitkileri ziyan eden hastalığın adıdır. Bitkilerin başı sarardığında, gövdesi kuruduğunda çor hastalığının bitkileri ziyan ettiğine inanılır. Ormanda ağaçların mevsimsiz sararması ve kurumasının da çor hastalığından dolayı olduğuna inanılır (Gazanfargizi, 2019). İşin ilginç tarafı şu ki, çor hastalığı her bitkiyi ziyan etmez. Çor belirli bir kutsallığı olan bitkiyi ziyan eder (Gazanfargizi, 2011). Burada yine gaip ile belirli bir bağlılığın göründüğü aşikardır. Çünkü kutsal olarak bilinen bitkilere çor hastalığının ziyan vermesi gaip ile bağlılığının ve dolayısı ile Çor iyesinin izlerini taşımakta olduğunu göstermektedir. Örneğin, Çor iyesinin koruduğu bahçeden hırsızlık edenin başına bir bela gelir. Yahut yılan vücuduna girer. Bu durum aslında bahçe sahiplerinin rahatlıkla bahçelerini bırakıp gitmesine, hırsızdan yana rahatsız olmamasına ortam oluşturur (Gazanfargizi, 2019). Genel olarak, Tengricilikte her şeyin bir iyesi olduğu için çevrede görünen ne varsa saygı ile yaklaşılır, ihtimam gösterilirdi. Aksi takdirde o nesnenin iyesi (sahibi) sinirlenir ve bir fenalık yapar. "Girilen boş eve selam verilmeli, evden çıkarken "ev size emanet" söylenmeli, bahçeden bir şey koparırken iyesinden izin alınmalı ve s.” (Acalov vd, 2005:51).

Çer ve Çor sözlerinin açılımı da ilgi çekicidir. Bu sözlerin bir şekilde yer sözü ile ilintili olduğu bir gerçektir. Altay Türkçesinin yazı dilinde Türkçe kelimelerde ön seste çoğunlukla y- sesi korunurken azımsanamayacak kadar kelimede de y->c- dönüşümü bulunmaktadır. Tatar Türkçesinin Anlatmalı Sözlüğünde (1981, C. III,) kök hâlde, türemiş, pekiştirmeli, birleşik kelime, yansıma, ikileme şeklinde (cidĩ “yedi”, cidĩgen "yedigen”, cidĩyıllık "yedi yıllık", cinel "hafif”, cinĩley- "hafifle-", cir "yer”, cir-kük "yer gök”, cirlĩ “toprak sahibi, cilbî̃-cilbî̃ "püfür püfür”, ceyĩn-kışın "yaz kış” vb.) c- sesi ile başlayan 450 civarında Türkçe madde başı kelime bulunmaktadır. Bu kelimelerin de büyük çoğunluğu i, î, e, ü (bilhassa i) gibi ince sıradan ünlülerden önce

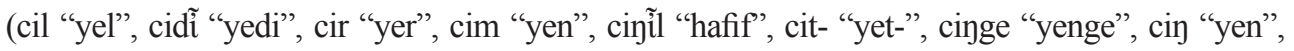
cin- "yen-"; cĩbĩ- "1slan-”, cîlĩk "ilik”, cĩp “ip”; cey- "yay-”, cey “yaz”, ceye "yay”, ceyev "yaya”, cerĩn "gelecek yıl”; cürme- "elle dik-" vd.) gelmektedir. Ancak a, 1, o gibi kalın sıradan ünlülerden önce gelen (cayna- "parla-, parılda-”, calpay- "büyü-, yetiş-”; cılı "sıcak”, cır "türkü”, cıy- "yı̆ğ", cıyır- "büz-, buruştur-", cılbır-cılbır "parıl parıl"; comak "bilmece", cot "hayvanların açlıktan kırılması, kırım” vd.) epeyce kelime de vardır (Alkaya, 2017:24). Göründüğü üzere çer ve çor sözlerinin o ve ya bu şekilde yer sözü ile çok yakın alakası vardır. Örneğin, Sibir Türklerinde Yer iyesi - Çir iyesi şeklinde mevcuttur (Beydili, 2015: 25). Çor sözünün çir sözünden türediği kuvvetle muhtemel. Çünkü çor da topraktan çıkan bitkiyi etkiler. Belli ki, çir sözü yer şeklinde dilimize geçse de, çor sözü olduğu gibi kalmıştır. “Azerbaycan dilinde eski Türk dillerine has /y/ sesi yerel özellik taşısa da, bazı durumlarda/ç/ sesinin parallel şekilde kullanılmakta, yahut sesdüşümü 
gerçekleşmekte: /yuyunmak-çimmek/, /yön-çön/, /yetmek-çatmak/ ve s. (Gurbanova, 2014:96). Çer ve Çor sözleri dikkatlice incelendiği zaman “yer” sözü ile benzeşdiği görülmektedir. İyelerin Çer ve Çor şekline düşmeleri, kanımızca, belirli bir sürecin sonucudur. Öncelikle, şunu belirtmemiz lazım ki, Türkçe sesdeğişimi yaygın bir olaydır. Örneğin, ç-c ve c-y sesdeğişimi hakkında Tatar Türkçesinin Anlatmalı Sözlüğ̈̈’nde de geniş bilgi verilmiştir (Alkaya, 2017:24). Biz elbette, bu örneklerle Çer ve Çor sözünün Yer iyesi şeklinde olduğunu söylemiyoruz. Amacımız her iki sözün bir şekilde "yer" daha da netleştirirsek "toprak" ile ilintili olduğunu göstermektir. Beydili çalışmasında "yir-sub"un "kutsal yer ve su ruhları" anlamında değil de "toprak" anlamında kullanıldığını belirtmiştir (Beydili, 2015: 52). Buradan yola çıkarak Çer ve Çor sözlerinin de toprak ile ilintili olduğunu söylemek mümkündür.

\section{3. Şulum iyesi/Bizden yeyi}

Azerbaycan'da çok yaygın diğer bir meşhur ifade ise "şuluma benziyorsun", "şulum gibisin" (Gazanfargizi, 2011) ifadesidir. Bu ifade genelde üstü başı pinti, kirli, bakımsız giyinen insanlara kullanılır. Şulum sözü bir deyimde dilimizde kalmışdır. Eski etnonimlerden “çul”, kanımızca, "Çulım” sözünde mevcut olmuştur. Bu söz 19. Yy'da Tambov vilayetinde yaşamış Çulım Tatarları ile alâkalıdır. Sözün kökü “çul”, "ım” ise ektir. Belirtelim ki, Bulgar tayfasından çelmat, Altaylardan çelkan, Kırgızlardan çılpak/çulbak etnonimlerinin temeli gibi görünmektedir (Radlov, 1989: 293). Etnonimin Şulması, şumnası, şimnusı, şolması, şulmı, şulbısı, çulbısı, çulme varyantları da mevcut, Mitoloji sözlükteki açıklamasına göre Ahrimen’den alınmış sözdür. Kötü ruhu ifade eder (Tokarev, 1988: 647).

Şulum, çulum, şulbusu, çulbusu gibi çeşitli adları olan iyenin en büyük özelliği pasaklı insanlara musallat olması. Şulum ve çulum sözlerinin aynı kökenden geldiği Türklerde çok yaygın ş/ç seslerinin yer değişiminden anlaşılmaktadır. Türkçelerdeki seslerin yerdeyişimini İlahe Gurbanova kitabında genişçe açıklamakta: "Türk dillerinin eski çağında bazı fonetik unsurlar ortak sayılsalar da sonradan ana Türkçe'de ikilem geçirmiştir (Gurbanova, 2014: 96). ş/ç seslerinin yerdeyişiminden N.Baskakov da bahsetmiş ve $c$ sesinin Oyrot dilinde ş ve ç şeklinde olduğunun altını çizmiştir: şık-çık, şolpon-çoplon vs. (Baskakov, 1972: 28). Gösterilen örneklerden şulum, çulum, şulbusu, çulbusu şeklinde yazılmış sözlerin hepsinin aynı anlam ifade ettiğini söylemek mümkündür. İsmi farklı şekilde yazılsa da bu iye ait olduğu tüm Türklerde pasaklı insanlara musallat olur, onları temiz kalmaya mecbur eder. Özellikle, Şulum'un görüntüsünün betimlenmesi de dikkat çekicidir: "Şulum iyesi kat kat zevksiz giyer, saçları hep dağınıktır, kendisi gibi olan insanlara da musallat olur, onları rahatsız eder" (Gazanfargizi, 2011). Göründüğü üzere, aslında rahatsız edici iye gibi görünse de, insanın kendisini temiz tutmaya mecbur kıldığı için amacında iyilik olduğu aşikârdır.

\section{Sonuç}

Tengricilik'in gizemlerinin ortaya çıkması için iye ve onların özelliklerinin araştırılması şart. Günümüz halkbilimşinaslıkta iye denildiği zaman Batı'nın etkisi ile tanrı, ilah gibi kavramların akla gelmesi uzun süre onların doğru yönde araştırılmasına ve aşikârlanmasına engel olmuştur. Eski Türk inancında iye sahiptir ve sahibi olduğu nesnenin çevresinde yaşar. Yani, 
neyi ifade ederse, iyenin kendisi de odur. Tengricilik inancında var olan her şeyin bir iyesi olduğu için, eski çağ insanın çevresindeki her şeye karşı saygılı olmasını gerektirmektedir. Maalesef ki, bu durum Tengricilik hakkında daha bir çok konuların kapalı kaldığını göstermektedir. Araştırmamız sonucu anlaşıldı ki, Şulum, Çer, Çor iyeleri "kara iye" olarak literatüre geçse de, aslında yapılan saygısızlık sonucu zarar vericiye dönüşebilir. Tengri her şeyin sahibi, iyesi olarak gönderdiği varlıkları insanlara zarar vermesi için değil, fayda ve bereket vermesi için göndermiştir. İnsanları da onlara karşı saygılı olmaya mecbur etmiştir.

İyeler hakkında kavram kargaşası sadece iye ve bizden yey ("ak iye" ve "kara iye") olmasında değil, bazen görevinin de yanlış ibraz edilmesinden de kaynaklanmış olabilir. Genel olarak, Tengricilik'e ait bir çok varlıklar İslam'ın etkisi ile "kılıf değiştirseler” de, araştırma esnasında nispeten derinliğe varıldığında onların iyeler olduğu görülmektedir. Çor iyesi saygısızlık gördüğünde bahçenin bereketini keser. Çer iyesi hayvanı hasta eder, hatta öldürür. Şulum iyesi ise pasaklı insanlara musallat olur ve böylelikle Şulum'un musallat olmasından korkan insan temizliğine dikkat eder. Dikkatlice incelendiği zaman anlaşılmakta ki, iye onlara karşı saygı gösterildiğinde yaratılışları gereğince fayda verir, saygısızlık gördüklerinde de zarara uğratır. Bu yüzden de iyeleri sinirlendirmemek lâzımdır inancı yaygındır.

\section{Kaynakça}

Acalov, A. (1988). Azerbaycan mifoloji metinleri. Bak1: Elm.

Acaloğlu, A, Beydili C. (2005). Esatirler, efsane ve rivayetler. Bak1: Şerg-Gerb.

Alıkaya, E. (2017). Tatar Türkçesi yazı dilinde ve ağızlarında y/c sesi üzerine. Uluslararası Türk Lehçe Araştırmalari Dergisi (türklad) Cilt 1, 1, 24-38.

Anokin, A. (1924). Materiali po shamanstvu u Altaytsev. Sb. MAE pri RAN - T.4. Moskva: Nauka.

Asker, R. (2006). Divan u lügat-it-Türk. Bakı: Ozan.

Baskakov, N. (1972). Severnie dialekti Altayskogo (oyrotskogo) yazika. Dialekt kumandintsev (kumandl-kiji). Moskva: Nauka.

Beydili, C. (2015). İstikbal halk edebiyatınındır. Bak1: Folklor İnstitu.

Buhârî, S. (1882). Lügat-ı Çağatay ve Türkî-Osmânî. İstanbul: Mihran.

Ferzeliyev, T. (1994). Azerbaycan folkloru antologiyası. Naxçıvan folkloru. Bakı: Elm.

Gazanfargızı, A. (2011). Gülüze Gurbanova ile söyleşi. Yazarın 2011 yılında alan çalışması zamanı yapılmış. Özel arşivinde kayıtlı.

Gazanfargizi, A. (2019). Ali Şamil ile söyleşi. (Yazarın alan çalışması zamanı yapılmış. Özel arşivinde kayitli).

Gurbanova, İ. (2014). Azerbaycan dili dialekt ve şivelerinin etnolingvistik tehlili. Bakı:Bilik.

Kaçalin, M. (2019). Kutadgu-bilik. İstanbul: T.C.Kültür ve Turizm bakanlığı.

Khaliq, A. (1995). Fahreddin Mubarekşah. DİA., XII, Ankara.

Menges, K. (1976). Turkskie idi "gospodin", nekotorie ego refleksi v turkskix yazıkax i paralleli v drugix yazıkovix semyax. Sb. Turcologica, Leningrad.

Nadjip, E. (1979). İstoriko sravnitelniy slovar turkskix yazikov 14-go veka na materiale "Xosrau i Şirin” Kutba. v 4-x kn., Moskva:Nauka.

Radlov, V. (1989). İz Sibiri. Moskva: Nauka.

Şerbak, A., Nasilov D (ed). (1969). Drevneturkskiy slovar. Leningrad: Nauka.

Tanyu, H. (1986). İslamlıktan önce Türklerde tek Tanrı inancı. Ankara: Ankara Üniversitesi.

Tokarev, S. (1987). Mifi narodov mira. 2 ciltte. 1.cilt. Moskva: Sovetskaya ensiklopediya.

Tokarev, S. (1988). Mifi narodov mira. 2 ciltte. 2.cilt. Moskva: Sovetskaya ensiklopediya. 